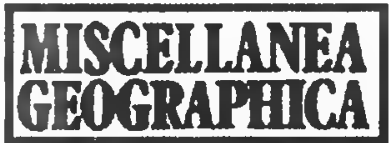

Vol. 122006 pp. 55-65

\author{
Elwira Żmudzka \\ Department of Climatology \\ E-mail: elwiraz@uw.edu.pl
}

\title{
PRESSURE FIELD OVER EUROPE AND NORTH ATLANTIC FAVOURABLE FOR THE OCCURRENCE OF CLEAR AND CLOUDY DAYS IN POLAND
}

\begin{abstract}
In this paper, results of research concerning circulation conditions favouring the occurrence of clear and cloudy days in Poland are presented. An analysis of the mean pressure field over North Atlantic and Europe on such days was performed, differences between the mean pressure on such days and the mean pressure from all the days of the period 1966-2000 were determined. The pressure field was characterised by mean daily values taken from grid nodes from the area with $\varphi 30^{\circ}-70^{\circ} \mathrm{N}$ and $\lambda 40^{\circ} \mathrm{W}-60^{\circ} \mathrm{E}$ (NCEP/NCAR database). The relation between the amount of cloudiness over Poland and pressure was estimated by means of linear correlation coefficient.
\end{abstract}

Key words: clear and cloudy days, Poland, pressure field, Europe and North Atlantic

As we know, one of the more important elements of climate, which is at the same time regarded as climate forming, in particular in modification of the greenhouse effect, is cloudiness. The time and quantity of the radiant energy flowing in, the substratum and air temperature, the quantity and form of precipitation depend on the amount and cloud genus. Clear days create conditions favourable to large radiation during the day and emission during the night; the situation is opposite on cloudy days. This has its consequences in the diurnal course of other meteorological elements. Particularly disadvantageous weather phenomena, e. g., drought, excessive precipitation, floods, thunderstorms and hailstorms, can be related directly to the cloudiness and the meteorological elements modify by it.

Despite of numerous partial research, the recognition of the temporal variability of the amount of cloudiness over Poland and of the circulation conditions from the climatologic perspective, in particular on large scale, is still - as opposed to the recognition in other European countries - relatively weak. The purpose of this paper is the determination of the circulation conditions described by the pressure distribution in the European-Atlantic sector, and favourable to the occurrence of clear and cloudy days in Poland. 


\section{MATERIAL AND METHODOLOGY}

To define clear and cloudy days amounts of cloudiness from main standard times $(06,12,18$ UTC) from 16 synoptic stations of IMGW located in the lowland Poland (up to $300 \mathrm{~m}$ a.s.l.) have been used. Daily sums of the amount of cloudiness in individual stations have been calculated and its were used as bases for the spatial averaged values in individual days of the period 1966-2000 (12 784 days). Clear and cloudy days were analysed; as the criterion of the definition the thresholds $\leq 4$ and $20 \geq$ octants were taken. Additionally, cloudless days and days with total cloudiness over Poland were analysed. The frequency of such days in individual months, seasons and years was determined. Analysis of the mean pressure field over the North Atlantic and Europe on these days was performed, differences between the mean pressure on these days and the mean pressure from all the days of the period 1966-2000 were determined. The largest and the smallest mean pressure values on these days and their differences with respect to the mean values from all the days of the period 1966-2000 were indicated (marked on the maps). The relationship between the amount of cloudiness over Poland and atmospheric pressure over Europe and the North Atlantic was estimated by means of the linear correlation coefficient. To describe atmospheric pressure mean daily values from the database NCEP/NCAR Reanalysis (1966-2000) were used. In the paper data from the grid nodes of the area $\varphi 30^{\circ}-70^{\circ} \mathrm{N}$ and $\lambda 40^{\circ} \mathrm{W}-60^{\circ} \mathrm{E}$ from the period $1966-2000$ were taken into account. The grid spacing is equal to $2.5^{\circ}$ of latitude and $5^{\circ}$ of longitude. Maps were drawn using the kringing procedure.

\section{FREQUENCY OF CLEAR AND CLOUDY DAYS OVER POLAND}

Clear days constituted $3.3 \%$ of all days (426 cases), that is, 12 days yearly on the average; cloudy days, $30.1 \%$ (3849 cases), that is 110 on the average (Table 1). In the individual seasons there were, on the average, from three clear days (in autumn, winter and summer) to four (in spring) and from 13 (in spring) to 44 (in winter) cloudy days.

Table 1.

Mean number of clear and cloudy days $(a)$ and its share [\%] in the total number of days (b) in individual months, seasons and year in Poland (1966-2000)

(Żmudzka, 2006)

\begin{tabular}{|c|c|c|c|c|c|c|c|c|c|c|c|c|c|c|c|c|c|c|}
\hline \multicolumn{2}{|c|}{ Days } & $\mathrm{J}$ & F & M & A & M & $\mathrm{J}$ & $\mathrm{J}$ & A & $\mathrm{S}$ & 0 & $\mathrm{~N}$ & D & DJF & MAM & JJA & SON & J-D \\
\hline \multirow{2}{*}{ 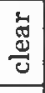 } & $a$ & 0.9 & 1.0 & 1.3 & 1.0 & \begin{tabular}{|l|}
1.4 \\
\end{tabular} & 1.0 & \begin{tabular}{|l|}
0.9 \\
\end{tabular} & 1.3 & 0.9 & \begin{tabular}{|l|}
1.5 \\
\end{tabular} & 0.3 & 0.7 & 2.7 & 3.8 & 3.1 & 2.7 & 12.2 \\
\hline & $b$ & 3.0 & 3.6 & 4.3 & 3.3 & 4.6 & 3.2 & 2.9 & 4.1 & 2.9 & \begin{tabular}{|l}
4.8 \\
\end{tabular} & 1.0 & 2.1 & 3.0 & 4.1 & 3.4 & 2.9 & 3.3 \\
\hline \multirow{2}{*}{$\begin{array}{l}2 \\
0 \\
0 \\
0 \\
0\end{array}$} & $a$ & 14.6 & 12.6 & 10.3 & 7.7 & 5.5 & 4.9 & \begin{tabular}{l|l}
4.9 \\
\end{tabular} & 3.5 & 6.5 & 7.9 & 14.7 & 17.1 & 44.1 & 23.4 & 13.3 & 29.0 & 110.0 \\
\hline & $b$ & 47.0 & 44.6 & 33.1 & 25.5 & 17.6 & 16.2 & 15.9 & 11.2 & 21.5 & 25. & 49. & 55.2 & 48.8 & 25.4 & 14.4 & 31.9 & 30.1 \\
\hline
\end{tabular}


Sometimes clear and cloudy days formed sequences. The longest sequences of both clear and cloudy days in Poland occurred in the cold half-year. The longest sequence of clear days lasted eight days. Such case occurred in March 1972 (12-19 March). In most months and in individual seasons single clear days were, however, the most frequent and their share in the total number of these days was greater than that of individual sequences of days. Only in April single days and two-day sequences constituted the same percentage of the total number of clear days. In October, two-day sequences had a larger share than single clear days and in January, four-day sequences.

Cloudy days, whose number during the year was nine times larger than that of clear days, formed longer sequences. For instance, at the turn of November and December 1997, a 17-day sequence occurred, and from 6 through 20 December 1970, a 15-day one. In March and in the period from May through September single days predominated in the total number of cloudy days. A particularly large percentage of them occurred in August. During the cold part of the year, short sequences - most often 2-day (October, November, December, February and April) and 3-day (January) had the largest share of the total number of cloudy days.

It is worth noting that among clear days five cases of cloudless days in Poland were observed, while among cloudy days, 53 days with total cloudiness. Cloudless days occurred in March, April, October and December, while those with total cloudiness, in the period from October through April and in June. Although in the period under investigation there were only 1-2 days per year with total cloudiness, they were not always scattered in time, but sometimes formed 2-, 3- and even 4-day sequences (total of eight sequences, constituting $38 \%$ days with total cloudiness). Such short sequences with total cloudiness occurred in Poland between November and January only.

\section{RELATIONSHIP BETWEEN THE AMOUNT OF CLOUDINESS OVER POLAND AND ATMOSPHERIC PRESSURE IN EUROPE AND THE NORTH ATLANTIC}

The mean amount of cloudiness over Poland which is connected with the number of clear and cloudy days is significantly influenced by the distribution of atmospheric pressure over Europe and the North Atlantic. During the whole year the increase of pressure over Central Europe, in particular over the area stretching from southern Scandinavia and the southern Baltic Sea to the Black Sea caused a decrease of the cloudiness over Poland (Fig. 1). The amount of cloudiness over Poland depended particularly strongly on the value of pressure over the area from Denmark and southern Scandinavia to the Black Sea in winter and spring (statistically significant correlation coefficients); in summer, over the North Sea and the areas around Baltic Sea; and in autumn, over the area stretching from the Ukraine to the Black Sea and the Aegean Sea. 
As the area over which the increase in pressure caused a decrease of cloudiness over Poland moved during the year, the location of the point in which this connection was strongest also changed. In winter and spring this point was located in central Poland; in summer, over the southern Baltic Sea; in autumn, over the Black Sea Lowland and the northern part of the Aegean Sea. A slightly different situation occurred in the individual months: in September and October this point was situated over Belarus; in November, over the Balkan Peninsula; in winter months, south-east of Poland (Ukraine - central part of the Carpathian Mountains - Black Sea Lowland); and in May, over Lithuania.

The increase of pressure over Greenland during the whole year, over the Greenland Sea and the Norwegian Sea in summer and autumn, as well as in the vicinity of Novaya Zemlya in summer was also favourable to the increase of cloudiness over Poland. The relationship between the amount of cloudiness over Poland and the pressure over those areas is statistically significant. In autumn it is even stronger than in the case of the relationship between cloudiness and pressure in the Black Sea region.

During the year the strongest relationships between the amount of cloudiness and pressure occur in summer (in July $r=-0.85$ ), while the weakest, in autumn (in November $r=-0.45$ ).
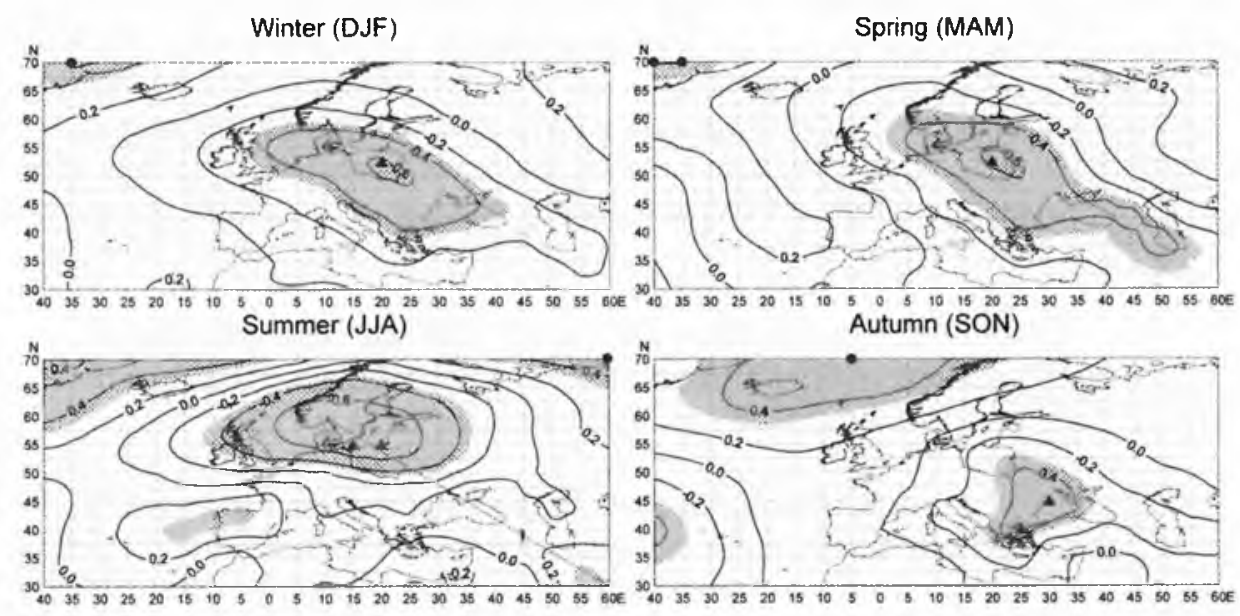

Fig. 1. Coefficient of correlation between the mean seasonal amounts of cloudiness over Poland with atmospheric pressure over Europe and the North Atlantic (1966-2000). The area of significant dependencies is shown. - - the highest value, $\mathbf{\Delta}$ - the lowest value 


\section{DIFFERENCES BETWEEN THE MEAN PRESSURE FIELD \\ ON CLEAR AND CLOUDY DAYS OVER POLAND AND THE MEAN PRESSURE FIELD IN THE WHOLE PERIOD 1966-2000}

The distribution of pressure on both types of days was investigated in months and seasons, but because of the similarity of the images obtained in consecutive months, only the pressure distribution in seasons was illustrated, directing attention to the months in which differences occurred.

During the whole year the range of the local high creates favourable conditions for the occurrence of clear days in Poland (Fig. 2). From October through April the high is related to the wedge of the Asiatic High, while in the remaining months, with the wedge of the Azores High.

The high with which clear days are related is particularly strongly extended in winter months. The pressure in its centre exceeds even $1035 \mathrm{hPa}$. The Icelandic Low is deep (in December and February the pressure within it falls below $990 \mathrm{hPa}$ ), with a vast trough stretching toward south-east as far as the Mediterranean coast of Africa.

In autumn and winter (in the months: April, August, September, October and December) the centre of this local high occurs over Belarus, while in spring (from January through March) it moves over Lithuania, and in summer (from May through July) it is located over the Polish coast of the Baltic Sea. In November it occur over the central part of the Carpathian Mountains. Such pressure distribution influences the inflow of air masses from the S-SE sector over Poland.
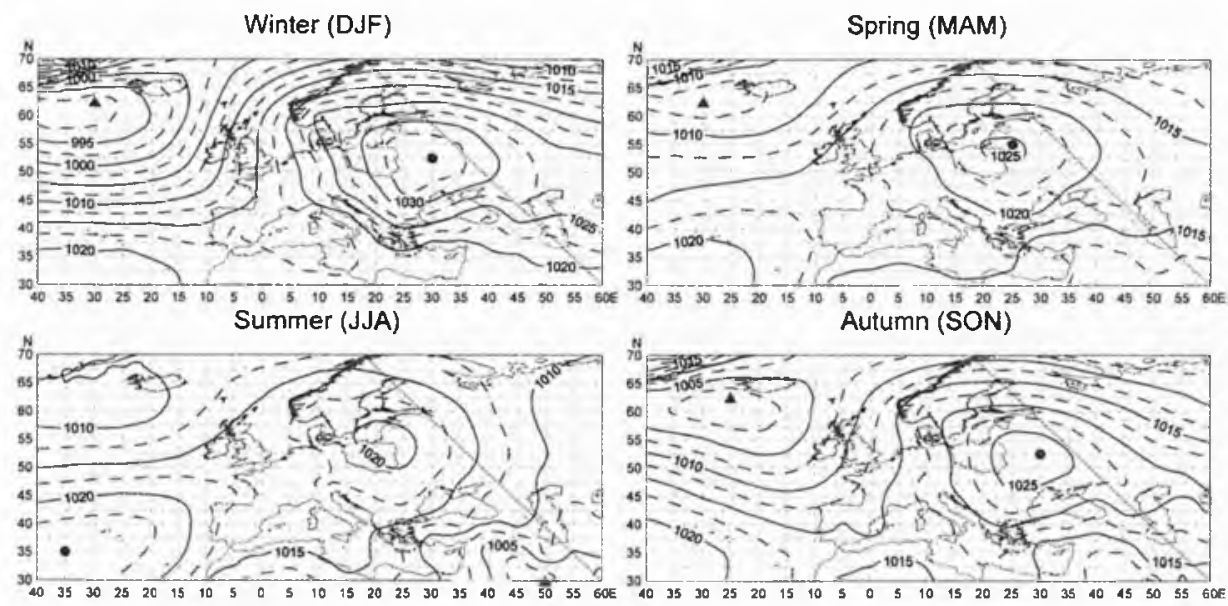

Fig. 2. Distribution of the mean pressure on clear days in Poland (1966-2000)

During the whole year the largest positive pressure differences between the mean pressure on clear days and mean pressure from all the days of the period 1966-2000 occur over the southern Baltic Sea and in its closest 
proximity (Estonia, Lithuania) (Fig. 3). The differences range from $6-7 \mathrm{hPa}$ in August and June to $18-20 \mathrm{hPa}$ in winter months, when, however, the number of such days is smallest. Positive differences occur in Northern, Central and Southern Europe. In the remaining areas lower pressure than the mean pressure of the whole period occurs. In autumn (except for September) and in winter as well as in July, the largest negative difference occur on the western coast of Europe (from $-15.8 \mathrm{hPa}$ in November to -4.9 $\mathrm{hPa}$ in July), while in spring (except for March) and in summer (except for July) they occur in the north-eastern part of the continent $(-3 \div-5 \mathrm{hPa})$.
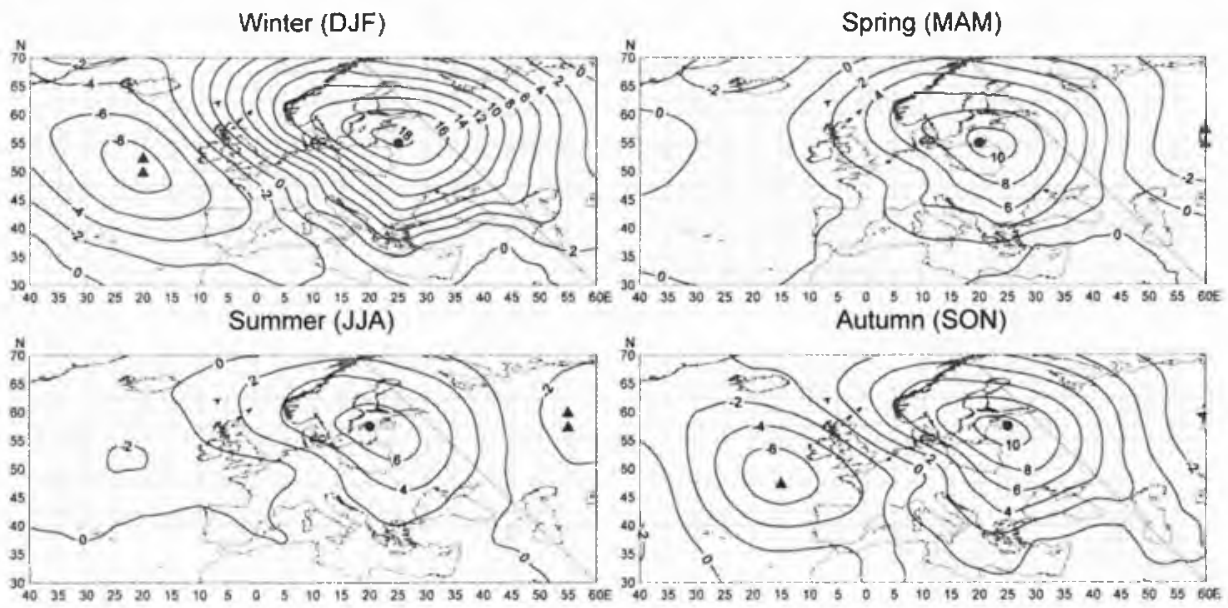

Fig. 3. Differences between the mean pressure on clear days in Poland and the mean pressure from all the days of the period 1966-2000

During cloudless days in Poland the pressure distribution over Europe and the North Atlantic is similar to that on clear days: a powerful high develops over Belarus, including Poland within its range (Fig. 4). It is related to the wedge of high pressure from Eastern Europe and Asia which reaches as far as the British Isles. On cloudless days this high is more marked than on clear ones. Relatively low pressure occurs only in the eastern part of the North Atlantic. Since during the entire 35-year-long period only five cloudless days occurred, the result can be regarded only as a strong confirmation of the characteristic features of the pressure distribution over Europe and the North Atlantic that favours the decrease of cloudiness over Poland.

On clear days the highest pressure occurs in summer months in the area of the average location of the Azores High, while in the remaining months it is related to the local high over Central Europe. The lowest pressure occurs in summer (from May through August) in the south-eastern end of the area under investigation, and in the remaining seasons (from September through April), in the vicinity of the average location of the Icelandic Low. The loca- 
A

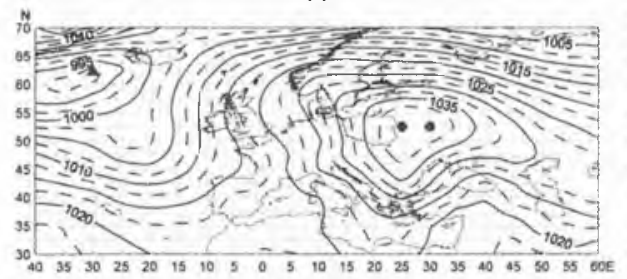

B

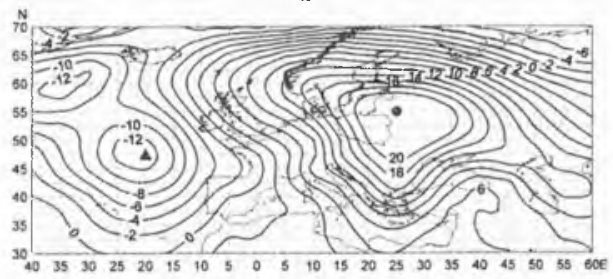

Fig. 4. Distribution of the mean pressure on cloudless days in Poland (A) and of differences (B) between the mean pressure on these days and on all the days of the period 1966-2000-year

tion of the area of the lowest pressure on clear days during the whole year is therefore similar to the mean image from all the days (Table 2). The occurrence of the area with the highest mean pressure on clear days and on all the days is similar only in summer. One should note, however, that in the period when a marked difference of pressure fields on clear days as compared with the mean image from the entire period can be observed, such days occur least often.

Table 2.

Highest and lowest values of the mean pressure from the period 1966-2000 and the geographic coordinates of the points where the values occurred

\begin{tabular}{|c|c|c|c|c|}
\hline \multirow{2}{*}{ Season/year } & \multicolumn{2}{|c|}{ Highest pressure } & \multicolumn{2}{c|}{ Lowest pressure } \\
\cline { 2 - 5 } & value & point & value & point \\
\hline Winter (DJF) & 1025.1 & $60^{\circ} \mathrm{E} 47.5^{\circ} \mathrm{N}$ & 995.8 & $30^{\circ} \mathrm{W} 62.5^{\circ} \mathrm{N}$ \\
\hline Spring (MAM) & 1022.1 & $30^{\circ} \mathrm{W} 32.5^{\circ} \mathrm{N}$ & 1006.7 & $30^{\circ} \mathrm{W} 62.5^{\circ} \mathrm{N}$ \\
\hline Summer (JJA) & 1024.5 & $35^{\circ} \mathrm{W} 35^{\circ} \mathrm{N}$ & 1000.1 & $50^{\circ} \mathrm{E} 30^{\circ} \mathrm{N}$ \\
\hline Autumn (SON) & 1023.7 & $35^{\circ} \mathrm{W} 70^{\circ} \mathrm{N}$ & 1002.4 & $30^{\circ} \mathrm{W} 62.5^{\circ} \mathrm{N}$ \\
\hline Year (J-D) & 1022.2 & $30^{\circ} \mathrm{W} 32.5^{\circ} \mathrm{N}$ & 1003.5 & $30^{\circ} \mathrm{W} 62.5^{\circ} \mathrm{N}$ \\
\hline
\end{tabular}

In autumn, winter and spring, the occurrence of a trough of low pressure over Poland is creates conditions favourable for the long-lasting occurrence of cloudy days in Poland (Fig. 5). Moreover, in winter the presence of a relatively shallow and larger than average, active centre of low pressure in southern Europe is favourable to the occurrence of such days in Poland. This centre stretches from the Gulf of Genoa to the eastern part of the Mediterranean Sea. This area constitutes the main region of cyclogenesis in this part of Europe (Trigo et al., 1999). In transitional seasons cloudy days occur when the range of the wedges of high pressure, in particular of the Asiatic High wedge, over Europe is smaller. In summer, however, the shift of the wedge of higher pressure related to the Azores High outside the area of Poland creates favourable conditions for the occurrence of such days; on the average, Poland is situated on its north-eastern end. Moreover, the frequency of lows over the Baltic Sea and the surrounding region increases. This is visible in 
the pressure distribution map in form of a closed isobar $1010 \mathrm{hPa}$ surrounding the area of lower pressure. A similar situation occurs in April and May, when, however, the centre of this low is located over the Polish coast of the Baltic Sea.
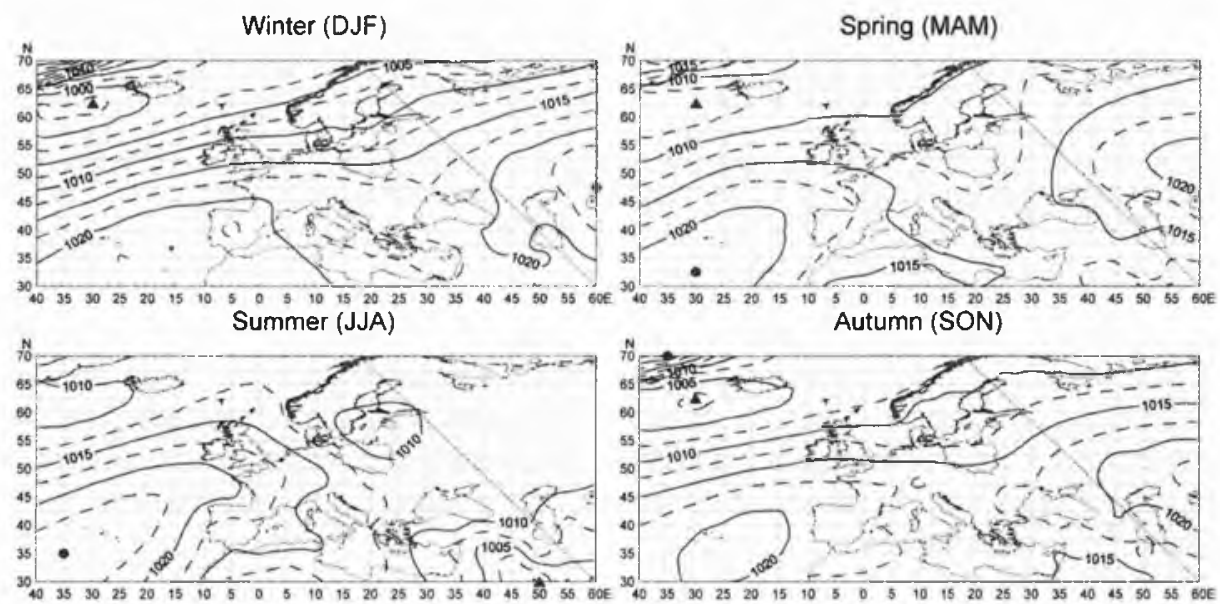

Fig. 5. Distribution of the mean pressure on cloudy days in Poland (1966-2000)

In the warm part of the year, when on cloudy days the axis of the Azores High wedge is orientated in the direction from south-west to north-east and its range is limited mostly to Western Europe, humid air from north-west flows in over Poland.

In the distribution of pressure that influences the occurrence of days with large cloudiness over Poland in individual months other differences with respect to the average image are visible. Some of the most important are:

- In January, the area of higher pressure located south of Poland is much smaller.

- In May the belt of higher pressure stretching, on the average, from the Azores High to Eastern Europe is broken over Central Europe; in that area, cyclogenesis is stronger.

- In June Poland is within the area of lowered pressure connected with the South-Asiatic Low and not, as is the case on the average during the whole period 1966-2000, at the edge of the Azores High wedge.

- In November and December areas with lowered pressure over the Mediterranean Sea are larger - stretching from the Gulf of Genoa to the eastern part of the sea.

The analysis of the differences of the mean pressure on cloudy and clear days from all the days shows that during the whole year lower pressure over Central Europe, most of all directly over Poland, creates favourable conditions for the occurrence of such days (Fig. 6). The largest negative differences were observed over the southern part of the Baltic Sea (in winter and summer) 
and over Central Poland (in spring and autumn). Only in November such differences occurred in the south of Poland and on the Hungarian Plain, and in December over southern Sweden. The largest negative differences range from $-1.4 \mathrm{hPa}$ in November to $-5.5 \mathrm{hPa}$ in August. Another region where the pressure is relatively low is the south-western end and - in most months (mainly from April through November) - the western end of the area under investigation.
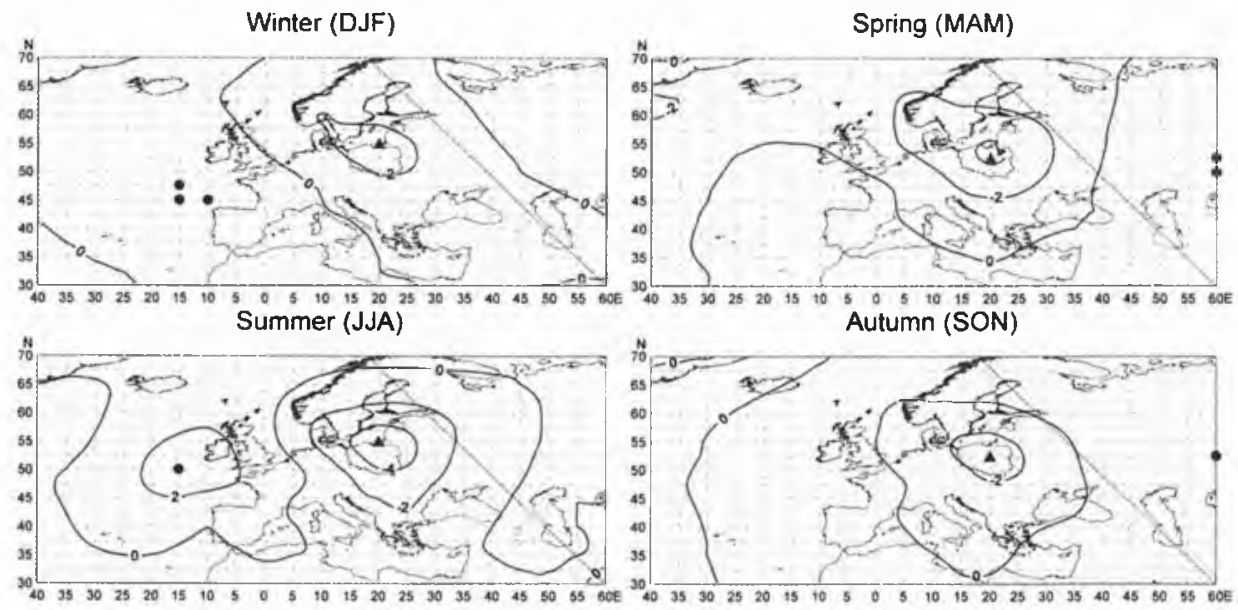

Fig. 6. Differences between the mean pressure on cloudy days in Poland and the mean pressure from all the days of the period 1966-2000

A complementary analysis of the pressure situation on days with total cloudiness over Poland in the warm half-year demonstrated that such days are related to the westward spreading of the high from Asia. At that time, air from northeast flows in over Central Europe. This advection is generated by the dipole pressure system: wedge (quasi-wedge) of the high pressure from Asia over Scandinavia - centre of low pressure in the region of the Black Sea. The eastern part of the Black Sea constitutes one of the four main regions where lows are formed in this part of Europe. They occur during the whole year, in particular in July and August (Trigo et al., 1999). On the average, during the year the occurrence of a vast trough enclosing the area from the central and eastern part of the Mediterranean Sea to the Baltic Sea creates favourable conditions for the occurrence of days with total cloudiness over Poland (Fig. 7). Additionally, the spatial distribution of the differences between the mean pressure on such days and the mean pressure from all the days of the period 1966-2000 shows the occurrence of a centre of low pressure occurs in the central part of the Mediterranean Sea and of the zones, probably related to them, of the fronts over the Balkan Peninsula and Poland. A wedge (quasi-wedge) of high pressure from Asia stretches over Scandinavia. 
A

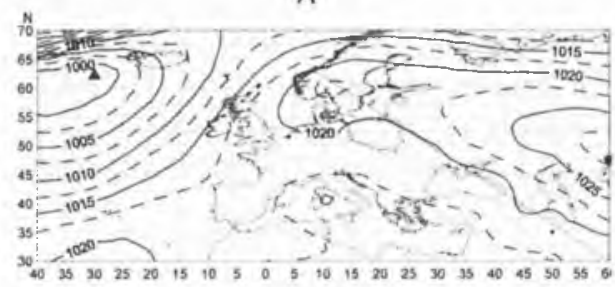

B

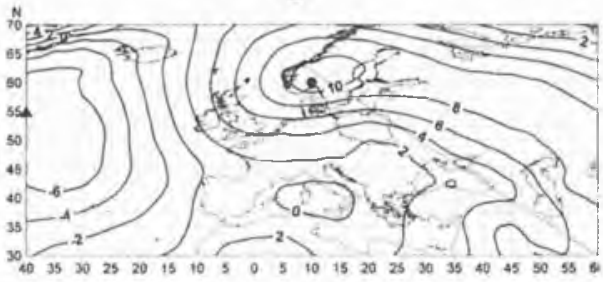

Fig. 7. Distribution of the mean pressure on days with total cloudiness in Poland (A) and of differences $(B)$ between the mean pressure on these days and on all the days of the period 1966-2000 - year

An analysis of the areas with extreme pressure values on cloudy days over Poland shows that both baric maxima and minima are usually located in the same areas as on the average in the whole period 1966-2000 (Table 2). Only in April, November and December the area of highest pressure was somewhat shifted.

Generalising, one can say that clear days occur during anticyclonal circulation, while cloudy days, during cyclonal circulation (which is usually only a weak trough). The increased frequency of lows over Central Europe (between $10^{\circ} \mathrm{E}$ and $30^{\circ} \mathrm{E}$ ), visible in its northern part in summer and in the south in winter favours the occurrence of large cloudiness over Poland. Cloudy days occur usually when advection comes from northwest. On the average, advection from the NE-SE directions with cyclonal and weakly gradient pressure field favours the occurrence of days with total cloudiness.

The centre of the high that creates conditions for clear days over Poland is located northeast of Poland. The inflow of air from the southern sector over Poland or else an advectionless anticyclonal situation is related to the pressure distribution described above. In individual seasons, except for summer, the highest pressure values from the whole area under discussion are related to the high over Central Europe, which distinguishes the distribution of the mean pressure on clear days from the mean pressure from all the days. Moreover, during the whole year, the largest positive differences between the mean pressure on clear days and the mean pressure from all the days are related to this high. The largest negative differences on cloudy days occur over the Polish coast of the Baltic Sea or over Central Poland. Only in November the area with largest negative differences is shifted southward a little (Hungarian Plain and south of Poland). Another region where these differences are relatively large is situated over the Atlantic, at the west coast of Europe: relatively high pressure creates favourable conditions for cloudy days while a relatively low pressure, for clear days in winter and autumn. In spring and summer, relatively low pressure in the north-eastern part of Europe favours clear days. It is worth noting that in spring and summer the point where the largest negative difference between the mean pressure on cloudy days and the mean pressure from all the days of the long-term pe- 
riod coincides with the point where the strongest negative correlation of the amount of cloudiness over Poland with atmospheric pressure over the area under discussion was observed.

To sum up, one can state that in winter, during stronger cyclonal activity, reflected in the occurrence of a trough of low pressure or a low in the mean pressure field over Central Europe, conditions for the development of large cloudiness persist. A similar pressure distribution favours cloudy days also in summer. This happens, however, less frequently, which results in smaller cloudiness. The formation of a high over Poland or one with a centre over the adjacent area, but with a wedge encroaching over Poland, restricts the development of cloudiness. Such situation happens more often in summer, but a decidedly higher pressure is observer in "clear" and in particular in "cloudless" highs in winter.

The location of the centres of the highest and lowest pressure in individual months and seasons both on clear and cloudy days changes little or not at all as compared with the average image. It is different only in the case of the baric maximum on clear days in the cold part of the year, thus during the period when the number of such days is smallest. At that time, the highest pressure is related to a high over Poland, not - as on the average in the long-term period - to the areas of high pressure over Eastern Europe. On cloudy days the maximal pressure is sometimes even higher than on clear days when the high is forming over Poland. Such situation occurs in summer. On the basis of research one can thus state that the occurrence of clear or cloudy days depends above all on the pressure distribution on a large spatial scale, influencing the direction of advection over the given area, thus also the type of air masses. The nephologic conditions in Poland are influenced by the development of circulation processes both in the sector North Atlantic - Central Europe and in South-Eastern Europe.

The knowledge of pressure distribution over Europe and the North Atlantic, which influences the increase or decrease of the amount of cloudiness over Poland, has a large importance for the forecast, since it gives information, although indirectly, about the amount of sunshine, radiation and temperature.

\section{REFERENCES}

NCEP/NCAR Reanalysis, 1966-2000

Trigo I., Davies T., Bigg G., 1999, Objective climatology of cyclones in the Mediterranean region, Journal of Climate, v. 12, nr. 6, 1685-1696

Ż m u d z a E., 2006, Pole baryczne sprzyjajqce wystepowaniu skrajnie dlugich ciqgów dni pogodnych i pochmurnych $w$ Polsce (1966-2000) [Pressure field favourable for the occurrence of extremely long sequences of clear and cloudy days in Poland (1966-2000); in Polish]. IMGW, Warszawa.

English translation: Matgorzata Mikulska 